\title{
Distance relationships and educational fragilities: A Student Voice research in digital third spaces
}

\author{
Luisa Zecca, ${ }^{a}$ Valeria Cotza ${ }^{b}$ \\ ${ }^{a}$ Università degli Studi di Milano-Bicocca, Italy, luisa.zecca@unimib.it, https://orcid.org/0000-0001-6216- \\ $\underline{9766}$ \\ ${ }^{b}$ Universitàdegli Studi di Milano-Bicocca,Italy,v.cotza@campus.unimib.it
}

\begin{abstract}
What impact did distance learning and education have on the most fragile students during the COVID-19 emergency? How is 'educational fragility' perceived by teachers and school educators, and how did this concept change during the school closure? How did children and young people perceive their remote learning experiences? The pandemic scenario forced to switch from face-to-face to distance educational relationships, triggering new fragilities and increasing digital inequalities. Therefore, in the digital environment of third space, a qualitative Student Voice research was conducted to collect students', teachers' and educators ' perceptions of remote schooling via semi-structured interviews. The study was implemented with working university students and school-going students with special educational needs, aged between 7 and 13 years, pursuing the teacher preparation aspect in the field of social justice. Preliminary results show that distance relationships fostered students' self-regulated learning and awareness of their own learning processes; however, only inpresence schooling is experienced as a real 'living-learning space.' All these aspects and especially the practitioners' awareness of the outcomes of distance education open up a new perspective towards an ecological theory of educational fragility, which could contribute to define new in-depth knowledge-construction tools in support of the education practice.
\end{abstract}

Keywords: Media education; social inequality; student participation; special educational needs; teacher education

\section{Introduction}

In Italy, according to a recent survey by Save the Children (2020), the COVID-19 lockdown exacerbated phenomena such as early school leaving and educational poverty, especially from Primary to lower Secondary School. A national research conducted by SIRD (Lucisano, 2020) on distance learning during the emergency found that only $74 \%$ of students were fully reached. The outbreak had devastating effects on children and young people with disabilities or Special Educational Needs (SEN), especially from socio-economically and culturally disadvantaged contexts (UNESCO, 2020), giving rise to an 'educational disconnection,' which is reflected in the 'missing pupils,' who too often become 'invisible.'

Educational discontinuity and disruptions heightened the difficulties of students who were already vulnerable and also revealed previously latent fragilities. So, in schools and educational contexts, the emergency triggered poverties that had previously been latent or dormant, forcing teachers, educators and researchers to address the critical issues that have long been challenging the activities and services whose role is to provide learning and socio-educational support. Therefore, the aims of this paper are to advance our understanding of the impact of distance learning - and more generally, to embrace a more holistic vision, of distance education - on students with SEN (for an overview of the concept at both national and international level: D'Alessio, 2014) and to examine representations and perceptions of support teachers, educators and fragile students about distance schooling relationships. We present an idiographic research designed to identify categories of analysis for experience in digital third spaces, via students' and practitioners' 'voices,' in keeping with the Student Voice approach (Grion \& Cook-Sather, 2013). 


\section{Theoretical framework}

\subsection{Fragility as 'digital inequality'}

Fragility is a culturally and historically situated construct, which affects the existential dimension of humanity as a whole, calling into play doubt and uncertainty (Canevaro, 2015); more specifically, 'educational fragility' encompasses disadvantages or difficulties (such as those in the social, cultural, familial, economic and linguistic spheres; learning and cognitive disorders; psychological, relational and behavioural problems), with both certified and non-certified diagnosis, that require treatments or care programs to prevent deviant behaviours and inequalities (Girelli, Bevilacqua, 2018).

Although our society is steeped in digital culture, technology as a means of overcoming social differences appears to be a myth: the so-called 'digital divide' means that for many, the right to Internet access continues to be violated (Van Dijk, 2005). Closing down schools underscored the gap between those who have access to computers and network connections and those who are excluded from the benefits of the digital society; but the emergency also brought to light another aspect of particular importance: it is not enough to equip students with PCs, tablets and broadband for the digital divide to end or narrow. Thus, beyond the relatively narrow issue of 'access to technology,' we find what Hargittai terms 'second level digital divide' (Hargittai, 2002) or 'digital inequality' (Hargittai \& Hsieh, 2013), that is, the differences in individuals' ability to make use of digital media, that is directly proportional to the level of socio-cultural capital. Many studies show that multiple factors (disability and SEN, ethnic background, gender or socio-economic and cultural status of one's family) affect digital inequality (Wessels, 2013), leading us to conclude that, for those living in these conditions of deprivation, an online-based approach is not ideal for creating an inclusive learning environment. This is especially so in our age of 'second modernity,' with its pervasive digital technologies and new post-industrial mode of production, which is typical of 'informational capitalism' (as defined by Castells [1996]); opportunities for using digital media and developing media literacy depend on individual resources, giving rise to social uprootedness, loneliness in pursuing selfrealization and communicative individualization (Gui, 2007). We should address the issue of how to make technological instruments and e-skills inclusive in these specific contexts, using environmental factors like technology as facilitators designed for children's functioning, according to the frame of ICF (International Classification of Functioning, Disability and Health). But the lockdown disrupted already precarious social equilibriums, worsening conditions of fragility to the point that some people were denied fundamental rights (such as education).

\subsection{In the third space: Teacher Education for Social Justice}

The distance relationships imposed by the pandemic forced us to create and leverage virtual places of active learning building and negotiation of meanings, that is, 'third spaces' characterized by a continual process of hybridization; these are dimensions (physical or virtual, as in our case) that encourage a more egalitarian dialectical relationship among people beyond the bounds of conventional hierarchical social structures (Bhabha, 1990). Among the multiple interpretations of third space, we appeal to those that see it as a bridge between different types of experiences (Elsden-Clifton \& Jordan, 2015, pp. 2-3) - which has the power to introduce us into non-traditional literacy learning and participatory paradigms (Pane, 2009, p. 70) - and a conversational space of critical research and radical resistance, with the capacity to generate democracy. As Potter and McDougall (2017, pp. 4-6) have reminded us, a technology-enhanced and digital third space setting is an educational experience in itself, in which voices can be heard and knowledges can be co-constructed thanks to more functional ways of conceptualizing teaching and learning. Their two framing questions are of great significance for our study (p. 7): what happens to people doing education in a digital third space? How do engagements in the digital third space influence practices back in the second space? They revisit the meaning of media languages in the third spaces of our 'informational society,' where a mutual relationship between those who create knowledge and those who receive knowledge is generated (Hallman, 2012, p. 7; for the relational aspects, see also Taylor, Klein \& Abrams, 2014). Within this perspective, the intersection between fields not only affects the relationship between student and teacher, but also enables us to look beyond the traditional binary distinction between practical and academic knowledge: as experienced by Zeichner (2010), creating third spaces for Teacher Education means opening real intermediate spaces of transformation located between two or more contexts of experience. According to the theory of Teacher Education for Social Justice (Cochran-Smith, 2004), a teacher should be a reflective practitioner and researcher (Schön, 1993), able to promote agency and engage in advocacy, who strives to ensure that the school functions as a 'social elevator.' 


\section{Research design}

\subsection{Research questions and context}

In light of the 'sensitizing concepts' (Charmaz, 2003, p. 259) we have identified above, we formulated two preliminary research questions, in relation to practitioners and students in compulsory schooling.

1. How is 'educational fragility' perceived by teachers and school educators, and how did this concept change during the school closure?

2. How did school-going students perceive their experiences and relationships of distance education?

The research data was collected from April to June 2020 in collaboration with 13 working students (teachers and school educators enrolled on a Master's Degree Course in Education, working in Primary and lower Secondary Schools), who were attending an e-learning course on design and evaluation of educational services. The student-teachers themselves raised the need to give voice to their own fragile students, who were often forgotten or deprived of the full right to speak. Thus, we implemented a qualitative-exploratory research (Lumbelli, 1984), which partially transfigured the traditional Student Voice approach, also by pursuing the teacher preparation aspect in the field of social justice, through the voices of trainee teachers and school educators themselves.

So, the aim is to examine in-depth representations and perceptions (both cognitive and emotional) of support teachers, school educators and their fragile students about distance schooling, for both personal and professional growth purposes.

\subsection{Methodology, participants and research tools}

13 working university students were invited to reflect not only on their practice, but also on the tools required to conduct a project committed to furthering social justice goals. Therefore, we reflected on the co-construction of data and meanings, adopting the constructivist Grounded Theory methodology (Charmaz, 2014) and the in-depth interview as its leading qualitative tool for both research and training purposes (Tusini, 2006). Hence, we designed a study in third spaces that combines methodological contaminations from field research and professional education development (Bove, 2015), working collaboratively on two non-directed and semi-structured protocols: the first aimed at school-going students (see Table 1) and the second to working students themselves (see Table 2).

Table 1. Profiles of the interviewed school-going students

\begin{tabular}{lllll}
\hline Interviewee's name & Age & Level of school attended & Location of school & $\begin{array}{l}\text { Certified diagnosis } \\
\text { (yes/no) }\end{array}$ \\
\hline G. (male) & 11 & Primary & Como & no \\
A. (male) & 10 & Primary & Buccinasco (MI) & no \\
P. (male) & 11 & Primary & Buccinasco (MI) & no \\
C. (female) & 13 & lower Secondary & Borgomanero (NO) & no \\
D. ${ }^{1}($ male) & 12 & lower Secondary & Collegno (TO) & no \\
M. (male) & 13 & lower Secondary & Lecco & yes \\
G. (female) & 10 & Primary & Buccinasco (MI) & yes \\
Fe. (male) & 11 & Primary & Limbiate (MB) & yes \\
L. (female) & 8 & Primary & Basiano-Masate (MI) & yes \\
Fr. (male) & 7 & Primary & Solaro (MI) & yes \\
\hline
\end{tabular}

23 interviews were conducted on Google Meet platform, video-recorded (with the consent of the participants of age and of the minors' parents) and literally transcribed; non-verbal communication (silences, wandering eye movements, facial expressions, nervous laughter, etc.) was observed for accessing interviewees' moods and implicit meanings. The 13 working students were interviewed by the other members of the team between 6 and 20 June 2020 (average interview duration: $1 \mathrm{~h} 15$ '), following a jointly validated protocol, divided into five sections (professional experience; interviewee's representations of educational fragility and inclusion; interviewee's perception on how students perceive his/her person and support; professional role and methodology; interviewee's experience of distance education). With regard to schoolgoing students, they were identified by the working students themselves within their respective work environments, from among the pupils they were currently working with; combining their professional development task with the habitus of researcher, the student-teachers themselves interviewed their own fragile students, allowing a relaxed climate of mutual trust to be established. So, between May 25 and July 23 2020, 10 interviews (average duration: 20') were conducted with

${ }^{1}$ D. was interviewed by a PhD student on the research team, who supported him as a (distance) school educator during the lockdown. 
students aged between 7 and 13 years ( 7 from Primary and 3 from lower Secondary School), who presented: learning and development disorders, autism spectrum, language issues, conduct disorders and socialization difficulties, attention deficit and hyperactivity, oppositional behaviour or familial and social disadvantages. This protocol, again jointly validated, was divided into three parts (questions to elicit the students' memories of school before the lockdown; questions inviting them to reflect on their experience of distance learning; questions soliciting more general judgements about this unusual period, also asking the interviewees to imagine the near future and put forward their 'own proposals' about school life).

Table 2. Professional and geographical profiles of the interviewed teachers and educators

\begin{tabular}{lll}
\hline Interviewee's name & Professional role & Location of work \\
\hline Alessandro Sa. & day centre educator & Borgomanero (NO) \\
Alice Se. & school educator & Monza \\
Serena C & school educator & Castellanza (VA) \\
Erica O. & cooperative coordinator & Meda (MB) \\
Carlotta F. & school educator & Buccinasco (MI) \\
Nicoletta B. & school educator and communication & Calolziocorte (LC) \\
& assistant & \\
Greta C. & classroom teacher & Varedo (MB) \\
Laura P. & support teacher & greater Milan area \\
Edoardo B. & school educator & Milan \\
Mariangela C. & support teacher & Milan \\
Martina C. & support teacher & Basiano-Masate (MI) \\
Riccardo R. & day centre educator & Como \\
Giulia F. & classroom and support teacher & Limbiate (MB)
\end{tabular}

\section{Data analysis, results and discussion}

Analysis is still in progress; we are now processing the data from the interviews. In keeping with our methodological framework, we are exploring and categorizing the data using the ATLAS.ti software; the emergent categories are being intersubjectively validated by two researchers (see Table 3).

Table 3. Preliminary emergent categories

\begin{tabular}{ll}
\hline Interviews with working university students & Interviews with school-going students \\
\hline $\begin{array}{l}\text { Fragility as an educational potentiality or resource; in } \\
\text { particular as: }\end{array}$ & $\begin{array}{l}\text { Re-designing learning environments by students } \\
\text { themselves, which includes: }\end{array}$ \\
$\begin{array}{ll}\text { 1. a latent potentiality } & \text { 1. the self-regulated learning (autonomy) } \\
\text { 2. a transformative strength } & \text { 2. the awareness of the own learning processes } \\
\text { 3. a resource for generating reflections } & \text { 3. school as a real 'living-learning community' } \\
\text { 4. an opportunity to reflect on fragility } & \end{array}$
\end{tabular}

A new perspective towards an ecological theory of educational fragility

\subsection{Through the voices of working students: Towards an ecological perspective of educational fragility}

A first key category that emerges from the analysis is fragility understood as an educational potentiality or resource, in contrast with the most common interpretation of fragility as a weakness, flaw, limit or difficulty. Educational fragility was represented by the interviewees as:

1. A latent potentiality, waiting to be seen, heard and understood;

2. A transformative strength for exploring how to offer appropriate support to the people we care for;

3. A resource for generating reflections about the relationship between teacher and student;

4. An opportunity to reflect on the fragility of teachers and educators and, by extension, of contexts;

Hence, fragility offers us the possibility to change our pedagogical outlook, not only by viewing all fragile situations as 'learned situations' (Palmieri, 2016, pp. 91-92), but also by looking beyond the meaning most commonly attributed to 
fragility. A.Se.'s words well exemplify the alternative view of educational fragility as a secret potentiality, which requires a certain kind of listening and the opposite of an arrogant attitude on the part of the practitioner. Working on a student's fragility is an action to be undertaken jointly, in the context of a mutual exchange between educator and student:

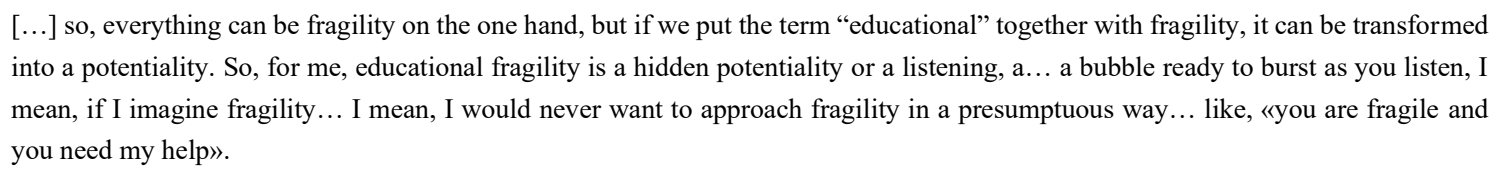

This is a stance that seeks to transfigure the negative implications of fragility, leveraging it to activate a process of self-reflection on the part of the educator on how best to address educational fragility. Once we accept that fragility cannot be reduced to a mere special educational need, it follows that the idea of 'fragility as a potentiality' is in itself a resource: the fragilities of the students are mirrored in the fragilities of their teachers and educators and vice versa. Thus, the fragility of students speaks to the fragility of practitioners, whose self-understanding triggers a process of empathy and transformation of limits into strengths, as M.C. pointed out:

[...] educators as human beings are partly fragile and especially when I was working at a residential care centre, I learned that the main thing for educators is to understand their own fragile points and ideally to transform them into strengths, because they can help you to better understand the difficulties of the person in front of you, because he/she might have the same difficulties as you; so from the point of view of empathy, fragility is seen as a positive and we put it out there. Educational fragility could also be in a negative sense the difficulty of putting yourself out there, for me that is a fragility.

M.C. also said: «It's as though people have so many little cracks and you can stand there looking inside, peeking at what's inside». This is an emblematic metaphor of the gaze of the educator, who cannot overlook - as many interviewees' comments reflected - the key notion of 'context,' understood as a microsystem, that is, a frame of activities, roles and relationships of which the developing individual has experience, that has particular concrete characteristics, and includes other people with certain characteristics of personality, temperament and belief systems (Bronfenbrenner, 1986). Indeed, a key category for the interpretation of our results is precisely the fragility of educational contexts, which crucially can exacerbate - or even generate - the educational fragilities of children and adolescents. The interviewees specified that fragile educational contexts are those that do not cater for the educational needs of students, which thus require:

1. To be known in-depth, before quality educational and learning interventions can be implemented

2. To be approached, in order to work on them, from an ecological perspective

In the field of education, the context, in its both micro and macro dimensions, is crucial. During the lockdown, as also observed in an ongoing qualitative study led by Mortari (2020), the school setting that was functional to attaining good learning disappeared: the challenges of distance learning have reminded us that educational experiences and practices are closely interrelated with historically situated contextual features and that, as a result, the concept of 'fragility' should not be absolutized. From this perspective, some educational fragilities may occur as the obvious consequence of contexts that are unable to adequately respond to the needs of students, as E.O. highlighted:

Because, therefore, a lot of the time, in my opinion, the fragilities that we see are not really the child's... but the setting's, [the setting] which cannot respond to the child at that point in time, and so perhaps, by modifying something where we can, we may be able to draw out his competence a bit more.

For instance, it should be noted that some students, who before the particular circumstances of the pandemic had never shown any evident signs of educational fragility, now regressed or underwent a crisis (Fantozzi, 2020). The interviewees agreed that familiarity with the context «in all its variability» (C.F.) is a prerequisite for conducting quality educational and learning work; some of them, embracing a more systemic vision, proposed attending not only to the child, but also to the educational environment, working on the context and its components. A structural fragility emerges:

\footnotetext{
We need to work on the context we have in front of us [...] in this period, what has been the fragility? The fact that so many children could not get access as they were supposed to. Whether because they didn't have a computer, or because they are foreign [...]. And so, if we want to work on that, we need to modify the medium by which we go about reaching them. (E.O.)

[...] educational fragility in the relationship: I am also thinking about the failings in a certain sense that educational networks very often have, and that yes, constitute a fragility; because we speak about educational networks, because basically a network must support the child and then maybe some connection is severed and makes the whole network fragile and everything falls apart. (M.C.)
}

Therefore, a preliminary interpretation of the results prompts us to theorize an ecological perspective of the educational fragility, in the light of which other categories of analysis could also be better defined. In fact, as we shall see, the notion of 'educational context' also emerged as of great importance in the words of the school-going interviewees. 


\subsection{Through the voices of school-going students: Re-designing the learning environment}

Many parts of the students' interviews reveal the propensity of children and young people to re-design the teaching and learning environment, conceived as a three-dimensional environment that consists of context (knowing-how), content (knowing-that) and community (knowing-to). These voices about re-designing the educational environment are beginning to take shape as a true main category, which fits in the ecological perspective outlined above and includes:

1. The self-regulated learning (autonomy), especially in time management

2. The awareness of one's own learning processes

3. The notion of school (a highly formal educational context) as a 'living-learning space and community,' in which immediate bodily relationships play a key role

First of all, some students highlighted positive aspects of distance learning that could potentially be integrated into inpresence schooling, as suggested by D. when the interviewer asked him what he would propose changing about school after the pandemic:

[...] when one is sick, who is at home, can also do... the teacher can also put a computer and do distance learning with the computer, when one is sick and has to stay home.

Some e-learning practices and tools appear to facilitate the learning process, especially with regard to the time variable, which is perceived by many students as a leading variable for understanding content and performing tasks without being disturbed by time limits. We next cite two of the most emblematic interventions on this topic, in answer to the question: can you tell me three good things about distance learning, giving me some examples?

\footnotetext{
[...] you can understand the teachers' explanations better, because you can save it for yourself and record the video, so you have it on your phone and you can study better; or the explanation of history or geography: maybe the teachers send videos that explain you and you underline on the phone and it is better, because you have it on your phone. (C.)

[...] apart from the video lessons, which have a precise timetable, you can spend a bit longer on the other tasks. [...] Another thing is that... in doing things, that is, in doing the homework they give us, there is no time limit. (P.)
}

Especially in the words of the older children, we can identify an emergent category related to a subliminal process of re-thinking the concept of 'autonomy' in an educational context. Thanks to the support of multiple Learning Objects (such as videos that can be saved on phones and watched over and over again), many students seemed to have regained a certain degree of autonomy in the area of time management, in terms of the power to make decisions about how to manage their own learning, which in some cases seems to relieve the emotional and cognitive demanded by the learning work (above all in terms of time). The e-learning environment, by facilitating the access to lessons and contents, further reinforced the function of technology - and especially of smartphones - as a true 'prosthesis,' while also offering opportunities to link learning and playing (the so-called 'gamification'). As reflected in the use of certain terms that act as indicators (such as 'understand' and 'study better'), some students began to engage in true meta-reflection, and this was leading them to develop a certain degree of awareness of their learning processes:

[a bad thing about distance learning] Doing mathematics, where I don't understand. I would rather see Rebecca next to me; if she was there, I would understand better. (C.)

[...] you can't ask the teacher about things... for example, I don't understand this thing, I'll show her, maybe you don't understand it well, the teacher can't intervene in any way. (D.)

Awareness of one's own learning processes means being aware of the need to be supported by a specific person in order to better learn, but also developing a critical understanding of which features of a given context promote learning and which do not. Indeed, many students highlighted multiple negative aspects of distance schooling, especially concerning the context, that prevent authentic relationships both with the teacher and among classmates:

[...] Since there are so many of us, it is difficult for some teachers to be able to see all of us on the screen and so we have to ask for permission to answer and if a lot of people know [it], it's a mess, and it is very difficult for the teacher to choose you. [...] in the work that they don't give us in the video lessons, I mean the ones they give us to do on our own, to understand it is easier if the teachers explain it to you, instead of having to figure it out for yourself. (P.)

[...] at school, the connection is never lost, because we are in the classroom, but on the computer[,] the connection is always going down, so you can't hear properly and we understand very little. [...] like, people leave, because their connection went down, who say: «can you hear me? Can you hear me?», so it's not nice. (G., female)

As D. says, at home «you can turn off the microphone, turn off the camera and leave». Therefore, despite everything, the school is once again configured as a 'living space,' especially a space for friendship and socialization: all students miss «having break-time» with friends; Fe. would like to see and hug all his classmates again; P. particularly missed the gym, but above all, in his opinion, «it's nicer to be in the classroom doing the lessons than behind a screen». On being 
asked what they missed about school, some of the students answered in a very significant way: «I miss everything» (A.), «Friends, and that's it» (G., male). Furthermore, some students were afraid of losing their classmates. Therefore, school is first and foremost a physical space made up of bodies, which fulfils its educational function primarily via physical contact and gestures that ensure the immediacy (and spontaneity) of authentic relationships. In the end, after all, real school life can be summarized and understood in-depth thanks to the highly emblematic words of C.:

I miss the classroom, the break, my classmates, even the teachers. I also miss seeing and chatting with the janitors, even though they sometimes scold me. [...] during art or math classes when we do nothing, we should do something, but we chat because we don't understand anything and we in the desk at the back don't listen and talk for the whole hour. It's super fun! We arrange to meet at the bin to talk and pretend to sharpen pencils, beautiful... I miss a lot of things, especially these.

\section{Conclusions}

Listening to students about distance education brought to light the meaning that in-presence schooling has for children and youths: that is to say, a real 'living-learning place.' Indeed, a preliminary analysis of the interview data confirms our starting framework: when the 'second space' is missing (as during the prolonged school closure we have experienced), digital spaces can augment educational difficulties and social inequalities.

Furthermore, our interpretation of the results analysed to date suggests that awareness of the outcomes of emergency distance schooling opens up a new perspective of inquiry, prompting an ecological theory of educational fragility, which would include the fragility of contexts and not only of people, in keeping with the framework of ICF. Designing such a perspective could contribute to define new in-depth knowledge-construction tools in support of the practice of teachers, educators and professionals more generally (Hulon, Tucker \& Green, 2020), in order to derive more refined examinations and conceptualizations for re-thinking the individual interventions and how they fit into the educational work as a whole. Hence, the next step in the research will involve debriefing the participants to share the study outcomes.

\section{References}

Bhabha, H. (1990). The third space. In J. Rutherford (Ed.), Identity, community, culture and difference (pp. 207-221). London: Lawrence and Wishart.

Bove, C. (2015). Ricerca educativa e formazione. Contaminazioni metodologiche. Milano: Franco Angeli.

Bronfenbrenner, U. (1986). Ecologia dello sviluppo umano. Bologna: Il Mulino.

Canevaro, A. (2015). Nascere fragili. Processi educative e pratiche di cura. Bologna: EDB.

Castells, M. (1996). The Information Age: Economy, society and culture. Vol. I. The rise of the Network Society. Oxford: Blackwell.

Charmaz, K. (2003). Grounded theory: Objectivist and constructivist methods. In N.K. Denzin, \& Y.S. Lincoln (Eds.), Strategies for qualitative inquiry (pp. 249-291). Thousand Oaks: SAGE Publications, 2nd ed.

Charmaz, K. (2014). Constructing grounded theory. London: SAGE Publications, 2nd ed.

Cochran-Smith, M. (Ed.) (2004). Walking the road: Race, diversity, and social justice in teacher education. New York: Teachers College Press.

D’Alessio, S. (2014). Le normative sui Bisogni Educativi Speciali in Europa e in Italia. Verso un'educazione inclusiva? La prospettiva dei Disability Studies. In P. Gaspari (Ed.), Pedagogia Speciale e BES (pp. 217-244). Roma: Anicia.

Elsden-Clifton, J., \& Jordan, K. (2015, July). What's up DOCC? Creating third space courses in teacher education. Refereed paper presented at the annual conference of the Australian Teacher Education Association (ATEA), Strengthening partnerships in teacher education: Building community, connections and creativity, Darwin.

Fantozzi, D. (2020). Interdisciplinarità e bisogni educativi speciali in tempi di lockdown sanitario obbligatorio: una connessione reale anche in ambiente virtuale, Italian Journal of Special Education for Inclusion, 8(1), 138-148.

Girelli, C., \& Bevilacqua, A. (2018). Leggere le fragilità educative a scuola per intervenire. Una ricerca per sostenere $i$ processi di crescita degli studenti nelle scuole trentine. Trento: IPRASE.

Grion, V., \& Cook-Sather, A. (Eds.) (2013). Student Voice: prospettive internazionali e pratiche emergenti in Italia. Milano: Guerini.

Gui, M. (2007). Disuguaglianze in rete. Il divario di competenze e strategie d'uso di Internet nella teoria sociale e in due studi empirici su giovani italiani, Polis, 21(2), 245-273.

Hallman, H.L. (2012). Community-based field experiences in teacher education: Possibilities for a pedagogical third space, Teaching Education, 23(3), 241-263.

Hargittai, E. (2002). Second level digital divide: Differences in people's online skills, First Monday, 7(4). Retrieved from https://firstmonday.org/ojs/index.php/fm/article/view/942/864

Hargittai, E., \& Hsieh, Y.P. (2013). Digital inequality. In W.H. Dutton (Ed.), The Oxford handbook of Internet studies (pp. 129-150). Oxford: Oxford University Press. 
Hulon, S.I., Tucker, M.H., \& Green A.M. (2020). Virtual professional learning for in-service teachers to support teaching and learning in online environments. In R.E. Ferdig, E. Baumgartner, R. Hartshorne, R. Kaplan-Rakowski, \& C. Mouza (Eds.), Teaching, technology, and teacher education during the COVID-19 pandemic: Stories from the field (pp. 43-46). Association for the Advancement of Computing in Education (AACE). Retrieved from https://www.learntechlib.org/p/216903/

Lucisano, P. (2020). Fare ricerca con gli insegnanti. I primi risultati dell'indagine nazionale SIRD "Per un confronto sulle modalità di didattica a distanza adottate nelle scuole italiane nel periodo di emergenza COVID-19". Retrieved from http://www.edaforum.it/ojs/index.php/LLL/article/view/551

Lumbelli, L. (1984). Qualità e quantità nella ricerca empirica in pedagogia. In E. Becchi, \& B. Vertecchi (Eds.), Manuale critico della sperimentazione e della ricerca educativa (pp. 101-133). Milano: Franco Angeli.

Mortari, L. (promoter) (2020). La didattica al tempo del Covid-19: i vissuti degli insegnanti. Research study in progress. Retrieved from https://www.cislscuola.it/fileadmin/cislscuola/content/Scuola_e_formazione/2020/02_2020/6065_Mortari.pdf

Palmieri, C. (2016). L'educatore nei servizi: marginalità, svantaggio, disabilità, Annali online della Didattica e della Formazione Docente, 8(11), 85-97.

Pane, D.M. (2009). Third space: Blended teaching and learning, Journal of the Research Center for Educational Technology (RCET), 5(1), 64-92.

Potter, J., \& McDougall, J. (2017). Digital media, culture \& education. Theorising third space literacies. London: Palgrave Macmillan.

Save the Children (2020, September 4). La scuola che verrà. Retrieved from https://s3.savethechildren.it/public/files/uploads/pubblicazioni/la-scuola-che-verra.pdf

Schön, D.A. (1993). Il professionista riflessivo. Per una nuova epistemologia della pratica professionale. Bari: Dedalo.

Taylor, M., Klein, E.J., \& Abrams, L. (2014). Tensions of reimagining our roles as teacher educators in a third space: Revisiting a co/autoethnography through a faculty lens, Studying Teacher Education, 10(1), 3-19.

Tusini, S. (2006). La ricerca come relazione. L'intervista nelle scienze sociali. Milano: Franco Angeli.

UNESCO (2020, April 21). Adverse consequences of school closures. Retrieved from https://en.unesco.org/covid19/educationresponse/consequences

Van Dijk, J. (2005). The deepening divide: Inequality in the information society. Thousand Oaks: SAGE Publications.

Wessels, B. (2013). The reproduction and reconfiguration of inequality. Differentiation and class, status and power in the dynamics of digital divides. In M. Ragnedda, \& G.W. Muschert (Eds.), The digital divide. The Internet and social inequality in international perspective (pp. 17-28). London: Routledge.

Zeichner, K. (2010). Rethinking the connections between campus courses and field experiences in college- and universitybased teacher education, Journal of Teacher Education, 61(1-2), 89-99. 